\title{
Use of Peer Observation for Self-enhancement
}

Bal Ram Adhikari

\begin{abstract}
The present article concerns the use of peer observation, particularly in the context of microteaching, for self-enhancement. The study followed a mixed methods design comprising survey and focused discussion. The data were collected from prospective external evaluators of teaching practice who participated in the training session entitled Find Good Practices of Teaching Demonstrated by their Peers and Adopt and Adapt According to their Needs so as to find out the participants' perspectives on observing their peers' classes and benefits they reaped from the observation. Analysis of the participants' written and oral accounts reveals that peer observation is a rewarding learning experience; and observation is likely to be fruitful when it is preceded by self-inquiry, that is, identification of what the observer himself/herself is lacking and followed by critical reflection on the observed lesson and the observer's own practice. Also, the peer's weaknesses can be employed as a critical incident to question one's own teaching behavior.
\end{abstract}

Keywords: Adaptation, adoption, critical reflection, peer observation, self-enhancement

\section{Introduction}

Peer observation constitutes the core part of teaching practice. It has been recognized as the mandatory component of teachers' professional development with the assumption that both prospective and practicing teachers can benefit a lot by observing each other's classes. The cursory survey of some of the key publications in teacher training and teacher development (Head \& Tayler, 1997; Harmer 2008; Richards \& Farrell, 2010; Richards \& Lockhart, 2010; Wallace, 2010; Wragg, 2012) reveals the centrality of peer observation in teacher development in general and practice teaching in particular. Its centrality is conspicuously manifested in the teacher preparation program. The Bachelor's and Master's programs of Faculty of Education (Tribhuvan University) can be a case in point. Both B. Ed. and M. Ed. programs have prescribed teaching practice as the compulsory course for prospective English teachers and both the courses recognize peer observation as the inevitable component. The course entitled 'Teaching Practice' (542) prescribed to the M. Ed. fourth semester serves to illustrate the case. The course makes observation

and recording of peers' lessons and their analysis mandatory both in microteaching and actual teaching at school or college with a view to enhancing trainee teachers' professional experiences.

Peer observation is a negotiated collaboration between the observer and the observed in which teachers observe each other's practice, "focusing on teachers' individual needs and the opportunity to both learn from others' practice and offer constructive feedback to peers" (Victorian Department of Education \& Training, 2018, p. 8). In the case of microteaching, peer observation is a process in which a prospective teacher takes the role of an actual teacher and the rest take part as students of a particular level. It is a kind of "role-play or simulation" (Wallace, 2010, p.100) normally by trainee or prospective teachers. In other words, prospective teachers prepare themselves for actual teaching by teaching each other, and observing 
and evaluating each other's lesson in a training context.

As role-play, peer teaching requires participants to take on dual roles simultaneously as students of a particular level and critical observers of their peer's teaching. The first role necessitates them representing "a class or learners at level X (whatever that level might be)" (Wallace, 1991, p. 100). Participants are to be attentive, curious and should behave like actual school or college students. That is, they participate in the class, interact with the teacher and with each other, and share their ideas as in the actual class. The second role, on the other hand, requires them to be the critical observer of their peer's teaching on the basis of certain criteria and they even have to jot down their impressions of the lesson. Simply put, while performing the role of the observer, they watch the lesson carefully, evaluate it and make some value judgment about the teaching performance.

Given the centrality of peer observation in teachers' professional development, the present study aimed to find out the prospective external evaluators' views about the role that observation played in their professional enhancement.

\section{Review of Literature}

Rational behind the use of peer observation to enhance the professional practice of trainee as well as practicing teachers is well established, for it "enables teachers to build their individual capability and develop a shared understanding of effective classroom practice. It also allows teachers to build their capability in giving and receiving feedback" (Victorian Department of Education \& Training, 2018, p. 8). As a part of capacity building, peer observation is a process of watching the peer's teaching performance, obtaining information about his/her skills, knowledge and resources, and giving feedback on one or all of these areas as well as learning from the peer's performance. In principle, peer observation thus serves twin purposes: giving feedback on the peer's performance for his/her improvement on the one hand and learning from his/her performance for self-improvement on the other.

Observation that aims at improving the professional practice of the teacher being observed can be termed as other-enhancement, whereas observation that is driven by the desire to improve the observer's own professional practice can be termed as self-enhancement. Conventionally, peer observation means the former, i.e. watching the peer's lesson closely and imparting constructive feedback for his/her professional enhancement. This is the most widely recognized role of peer observation, particularly in the context of microteaching. The use of peer observation for the professional enhancement of observers themselves has been largely overlooked in ELT professional development and its value is least realized in the teacher education program despite the fact that "skillfully handled classroom observation can benefit both the observer and the person observed, serving to inform and enhance the professional skill of both people" (Wragg, 2012, p.2). In this regard, Victorian Department of Education and Training (2018) rightly recognizes the two-way contribution of peer observation as it "can benefit both the teacher being observed and the observer" because it provides, among others "opportunities to discuss challenges and successes with trusted colleagues and support the sharing of ideas and expertise among teachers" $(2018$, p. 8) The thrust of the argument is that peer observation is to be employed as a space shared by the observer and the 
observed where one can learn from the other.

Observation for other-enhancement is outward-projected in that the observer directs feedback towards the teacher being observed. To further explicate this notion, the observer's main object is to give feedback to the peer teacher for the sake of his/her professional enhancement. Whatever the observer learns from his/her peer's performance is the byproduct of observation. On the contrary, the second type of observation is mainly inward-projected in that the observer directs feedback towards himself/herself. That is to say, his/her main object is to learn from the performance of the teacher being observed. S/he may or may not give feedback to the peer whose lesson has been observed, for $\mathrm{s} /$ he is driven by the strong desire for self-enhancement through self-evaluation in light of what has been observed. Stressing the role of peer observation for self-enhancement, Harmer (2007) refers to Cosh and Woodward (2003) who posit that "the great development potential of peer observation is for the observer, not the person being observed" (p.420). Cosh and Woodward's position is substantiated by Hendry and Oliver's (2012) findings which reveal that while engaging in peer observation, observers learn how to use new teaching strategies, affirm their selfefficacy, and develop confidence in doing something that is seemingly too difficult to do. Drawing on the findings, Hendry and Oliver conclude that the process of observing is more valuable than "being observed and given feedback" (p.1).

While observing others, we are also observing ourselves. In this regard, philosopher Krishnamurti avers that the observer is the observed (1946). That is, the observer himself/herself also becomes the object of observation while observing others; the observer turns towards himself/herself. Its result is that there is a constant interaction between outward (other) observation and inward (self) observation leading to selfinquiry and self-knowledge. Self-inquiry or "questioning one's own assumptions while observing can be a genuinely intrapersonal development" (Harmer, p. 420). Critical self-observation has been identified as one of the key strategies of reflective teaching (Richards \& Lockhart, 2010) and reflective practice model of professional educational development (Wallace, 2010), both reiterating the fact that the observing teacher becomes critically aware of his/her own practice. To put it another way, "observing another teacher may also trigger reflections about one's own teaching" (Richards \& Farrell, 2010, p. 89). Participants observe their peer's lesson, evaluate his/her way of teaching, identify certain areas that they think went best or did not go as they had expected, reflect on these areas and think how they can adopt or adapt them in their own teaching. To put it simply, it is a form of self-directed learning in which the observer identifies a gap in his/ her own teaching knowledge and/or skill, explores the way of filling the gap and adopts and/or adapts the strength or desirable practice and reflects to what extent it works for him/her.

\section{Methodology}

The present study followed a mixed methods design that comprised survey and focused discussion with the university teachers who participated in a five-day training program entitled 'Teaching Practice External Evaluation Roster Training' conducted by Faculty of Education at Kathmandu Shikshya Campus, Satungal. The training aimed at preparing the M.Ed. level external evaluators for teaching practice. Successful implementation of peer observation during microteaching was one of the components of 
the training session that lasted for two hours and a half. In the session entitled 'Find Good Practices of Teaching Demonstrated by their Peers and Adopt and Adapt According to their Needs', my role as a facilitator was to help the prospective external evaluators to reflect on learning from observing others' lessons, explore 'good or desirable practices' of teaching, challenges of successful implementation of peer observation during microteaching and work out the solutions. Of these four key areas of the session, the present article concerns only the prospective external evaluators' reflections on observing their peers' classes during microteaching or in the actual professional setting and sharing their observation experiences primarily in written form.

As to the experience of learning from the observation of peer's teaching, the following questions were posed to them: a) Do you remember observing any of your peers' class? b) If yes, do you remember some aspects of his/her teaching that really impressed you? c) If yes, did you carry them over to your lesson later? and d) If yes, did it improve your teaching? With the presentation of these close-ended and open-ended questions, each of the participants was provided with a loose sheet of paper to recount their observation experiences and they were given 15 to 20 minutes to record. Before the collection of the responses, five of the participants presented their written experiences that led to an open discussion. The ideas shared during the discussion were noted down to supplement the written accounts. Of the total 49 participants, only 35 of them responded in the written form, whereas the rest either had no such experience to share or wished to share their experiences only orally during the open discussion session. The participants were coded P1, P2...P35 to ensure their anonymity. The written accounts and notes collected during open discussion were analyzed using content analysis, which involves "a careful, detailed, systematic examination and interpretation of a particular body of material in an effort to identify patterns, themes, biases, and meanings" (Berg, 2007, pp. 303-304). Further, I have used an interpretive approach to the analysis of the cases collected from the participants.

\section{Results and Discussion}

The following themes emerged from the analysis of the written and oral accounts: a) observation as a rewarding learning experience; b) focus of observation; c) necessity of dependency and anxiety of influence; (d) learning from the peer's weaknesses; and (e) the cyclic process of observation for selfenhancement.

\section{Rewarding Learning Experience}

The overwhelming majority (71\%) of the participants shared the experience of observing their peers' lessons in some point of their professional life in different settings. Some recounted the experience of observing the lessons as trainee teachers during microteaching or during actual teaching in school or college, whereas others had observed their peers' lessons as in-service school or college teachers.

Each of the responding participants recounted that observing the peer's class was a rewarding experience, for the observation provided them with an opportunity to recognize the missing part in their own teaching and to see how that could be addressed. The following reflective account exemplifies their learning experience: 
I was messy in presentation of key ideas to my students. I lacked the skill of presenting the ideas in a coherent order, that would often create confusion among my students. I observed my colleague's class twice or so. I was surprised to see how systematically he would present key points on the board and deal with each in a coherent way. I noted it in my diary \& committed to myself to using this teaching from the next class. (P1)

P1 observed his colleague's class in the actual professional setting. That is, he observed the lesson not as the partial fulfillment of teaching practice formally required by the institution. Rather, he was selfmotivated and self-directed, as he was critically aware of his own weakness as a teacher and he wanted to improve it by learning from the best practice of his colleague. His account sheds light on four aspects of observation: a) the use of observation for self-improvement; b) constant reflection on one's own practice and identification of the problem(s); c) attitude to learning from others; and d) trying out what has been learned from others in one's own teaching. Contrary to the conventional practice of using observation as a means of giving feedback to the peer, the responding participants shared the experience of deploying it "as a critical reflective device" (Peel, 2005 p. 489) for self-enhancement. They reflected on their own way of teaching and became aware of what was missing and identified the area that they wised to improve, observed their peers' lessons, noted mentally or in written form what went best in their teaching, and tried out what they had learned from the observation. The responding participants recounted that they experienced some positive change in their teaching after the observation of their peers' classes. The following can be considered as a representative voice:

I was really impressed by one of my peers' style of teaching [a] story, using pictures and arranging them in order and making the students tell the story from the pictures. I noted down this technique, went to my room, made a plan and taught the story like him the following day. My supervisor appreciated my way of teaching story. (P2)

Peer observation thus does have "a developmental function" (Head \& Taylor, 1997, p. 186) in helping the observer notice some gap in his/her own knowledge and skill, and fill in the gap with what s/he has learned from the peer. In this context, Peels (2005) cites Shortland who notes that "observation offers tremendous potential to promote self-knowledge and professional development, particularly when it is part of a continuing process" (p. 492).

\section{Focus of Observation}

The analysis of responses reveals that observation carried out by participants was purpose-driven, problem-oriented and self-directed. Put simply, each of them maintained their focus on certain aspects of their peer's teaching. Since they were observing their peer's lesson mainly in the hope of bringing about some change in their own teaching, the aspect they focused during observation was the aspect that they felt lacking in themselves or it was the aspect that they wished to improve. In other words, the focus of observation constituted the problem that they wished to solve so as to make their teaching effective as evinced in the following reflection:

When I observed my friend's grammar teaching class at secondary level, I found him presenting 
so many examples while teaching simple present tense. And students made many sentences based on the examples. They could construct rules themselves. But I used to present rules to students and would ask them to read the rules and make sentences. I knew that was not much effective. I liked my friend's way of teaching and adopted it in my teaching too. [P10]

The focus of P10 was the problem that he identified in his own teaching i.e. ineffectiveness of the deductive approach. Critically aware of his own practice and driven by the desire for self-improvement, P10 focused on the presentation technique used by his colleague which he, as confessed in the account above, found more effective than his own and adopted it to his subsequent grammar lessons.

It seems that the respondents were aware of the fact that "classrooms are exceptionally busy places" (Wragg, 2012, p.1) and there is every likelihood that the observer gets lost during observation if not wellplanned in advance. This is common particularly with the novice observer. Even the experienced observer is likely to lose the track of observation if $\mathrm{s} / \mathrm{he}$ is not clear beforehand about what to watch. Identification of a focus is a must for observation to yield a fruitful result. In their attempt to outline guidelines for peer observation, Richards and Lockhart (2010) clearly state that "observation should have a focus. The value of observation is increased if the observer knows what to look for" (p.24).

As to the focus of observation, the areas prioritized by respondents were found to be diverse. Table 1 summarizes the foci of their observation:

Table 1

Foci of Observation

\begin{tabular}{lc}
\hline Catalogue of the foci of observation & No. of respondents \\
\hline Clarity and fluency of English (pronunciation) & 23 \\
Techniques of content presentation & 15 \\
Motivation and engagement techniques & 8 \\
Use of materials & 2 \\
Subject matter knowledge & 2 \\
Classroom management technique & 1 \\
\hline
\end{tabular}

Since most of the respondents recounted their experience of observing two or more aspects of the lesson, the total number of respondents in Table 1 exceeds the actual number of participants (i.e. 35 ). Table 1 reveals that language was the most prioritized aspect of observation. Here language comprises clarity and fluency of English (pronunciation), word choice and grammar (in a descending frequency order).Classroom management techniques, on the other hand, were the least prioritized aspects. It implies that the overwhelming majority of the participants perceived language, pronunciation in particular, as the most problematic aspect of their teaching that they wished to improve by watching their peers' class. Alternatively, we can also say that clear and fluent English was perceived as the key to effective teaching. The following can be presented as a representative case:

I remember observing one of my colleagues' class. I was very impressed by clarity and fluency of his English. Neither too slow, nor too fast. After the observation, I also tried to carry it over to my 
lesson. Yes, it improved my presentation. [P15]

The participants showed their prime concern for presentation techniques after accuracy and fluency of language. Like language, presentation techniques such as presenting the grammar lesson with examples, contextualization, story telling, guiding students through different reading activities etc. characterized effective presentation and the observers wanted to improve these areas by watching their peers' performance. They seem to hold the assumptions that: a) efficacy of teaching is largely conditional upon the types of presentation technique that one adopts; and b) use of techniques is observable, learnable, and transferrable to one's own teaching context.

In terms of focus, some observers were uni-focused, while others were multi-focused. The unifocused observers primarily attended to only one aspect of teaching such as fluency and clarity of English, motivation, and presentation technique. The multi-focused observers, on the contrary, paid attention to more than one aspect of teaching such as language and presentation techniques, presentation techniques and use of materials, and subject matter knowledge and language. Multi-focused observation is the reality, for "lessons are complex events with many different activities occurring simultaneously" (Richards \& Lockhart, 2010, p.24). Practically, however, uni-focused observation is more effective than divergent observation because the observer gets the opportunity to explore breadth and depth of the teaching aspect being observed, and such an observed aspect is likely to be effectively transferred to one's own teaching. However, the single-minded observation necessitates the observer to identify beforehand what $\mathrm{s} /$ he wants to observe in his/her peer's lesson.

\section{Necessity of Dependency and Anxiety of Influence}

Adoption or adaptation of desirable practices from peer's teaching was one of the prime concerns expressed by participants in the open discussion after the submission of written responses. Five of them, in particular, were articulate about the risk of being swayed by others' teaching and adopting their ideas slavishly. Their concern has its roots in the anxiety of being directly influenced by others and losing one's own originality in teaching. On the one hand almost all participants agreed that observing peer's teaching was a transformatory learning experience, but on the other, deep down they expressed their concern over emulation. Here we can sense a conflict between necessity of dependency on others for learning good practices for one's own professional enhancement, and desire for claiming one's ownership over the teaching process. Simplistic imitation may add skills and techniques to one's teaching repertoire, but its contribution to professional enrichment is questionable. At this junction, Peel's (2005) reflection deserves special mention:

As an 'apprentice teacher', I was certain that POT (peer observation tool) could help me to modify my classroom behavior through imitation. By watching others, I could gain new or fresh insights.

But it proved not to be that simple. If observation was going to work for me it was clearly critical for me to notice 'good' teaching in others, and to be critically reflective. (pp. 494-495)

Hence, learning from observing should not be mistaken for the mere imitation of others' practice and carrying over desirable aspects to one's own teaching. Rather, observation necessitates the observer's 
critical engagement with peer's teaching and creative transfer of desirable aspect(s) to his/her own lesson. Criticality helps the observer to indentify strengths and weaknesses of the lesson being observed and find out desirable aspect(s), identify the gap in his own teaching and contemplate whether and how they can be carried over to his/her own teaching context. Likewise, creative transfer is a prerequisite for modifying other's desirable classroom behavior to fill in the gap in one's own teaching. Creative transfer stands closer to adaptation of desirable practices rather than their mechanical adoption.

The questions that surfaced the open discussion and ran through the written accounts were: a) Should the observer adopt or adapt desirable practices? And b) To what extent should the observer adopt or adapt them? The answers to these questions are subject to a myriad of factors such the nature of the areas being focused by the observer, his/her teaching experience, professional competence, critical engagement with peer's teaching, and art and skill of transferring desirable practices to his/her own teaching context. We can hence only offer a provisional answer that the observer should adopt and adapt what has been learned from observation with varying degrees of intensity. In practice, observers adopt certain aspects from their peers' teaching and adapt them to suit their own teaching situation. It was noticed that some teaching aspects lend themselves more to adoption than adaptation or vice versa. Let us consider the following account as the representative case of adoption:

I used to teach in an English school some years ago. I wanted to see how my colleague would teach reading. So I observed his lesson to see his techniques of teaching [the] reading text. He engaged students in multiple activities within 40 minutes. I used to teach reading just by lecturing and paraphrasing. After reflecting on the observation, I adopted his techniques in my classes as well. I found that the students were tremendously impressed with my new way of teaching. [P16]

The account by P16 typifies the case of adoption in which the observer almost directly transferred what he had watched in the colleague's class. In his case, direct adoption of teaching comprehension activities yielded a desirable result. Likewise, other participants recounted that adoption of techniques and resources proved rather fruitful. From this we are in a position to postulate that techniques, activities and resources employed in the classroom lend themselves to adoption, for their employment is observable, learnable and transferable. On the other hand, the participants' reflections also revealed that certain aspects of teaching are rather subtle and defy direct transfer from one context to the other as evinced in the following:

M.Ed. Microteaching: my supervisor commented that I lacked clarity in my English. There was a colleague highly appreciated for fluency \& clarity of English. The supervisor advised me to observe his presentation and see if I could slow down and maintain natural fluency like him. I observed. I noted down his way of speaking and reflected on my own. I also sat with him after the lesson. I planned and taught. I felt someimprovement in my teaching.(P19)

Unlike techniques and activities, aspects of teaching such as fluency and clarity of speaking cannot be directly adopted and transferred to one's own teaching. Rather, the observer can become aware of language-related areas such as fluency and accuracy in pronunciation, accuracy in grammar and word 
choice, pacing, and attitudes towards students, among others. In light of what has been observed, s/he can critically reflect on his/her own teaching behavior and contemplate how s/he can modify it accordingly. For these aspects of teaching defy direct transfer and can be actualized only over time, they are more adaptable than adoptable.

\section{Learning from the Peer's Weaknesses}

Unlike those participants who recounted learning from strengths of their peers, four of the participants recounted that they learned from their peers' weaknesses. Contrary to their expectations, they did not find their peers' teaching effective for some reason. That is, each of them had the feeling that something was not going well:

I observed the literature class of one of my colleagues teaching in M. Ed. He was good at content but

I was not satisfied with his language (problem). He tried to convince the students but he could not.

So, I realized that teacher's language is a considerable factor in the literature class.[P32]

Those who were aware of their colleague's failure in delivering the lesson effectively expressed some dissatisfaction, and each of them had the feeling that they would not be teaching the way their colleague was teaching. By implication, they were aware not only of the gap in the presentation observed and but also the way of filling the gap. It seems that they awakened to their own strength while coming across their colleagues' weakness.

These observers used their peers' teaching as a critical incident that "serves to trigger insights about some aspects of teaching and learning (Richards \& Farrell, 2010, p. 113). Critical in the sense that it was contrary to the observer's expectation, for $\mathrm{s} / \mathrm{h}$ e was there in the class to watch certain desirable practice. It made the observer pause for a moment and contemplate what it went wrong, then reflect on his/her own teaching and contemplate what could be the better way of addressing the problem. The observer was critically aware of "the negative classroom event" (Richards \& Farrell, p. 115) that increased his/her selfawareness as a teacher.

\section{Cyclic Process of Observation}

The analysis of responses clearly suggests that the observers passed through different yet interrelated and interactive stages. They did not make a giant mental leap from watching the peer's lesson to self-enhancement. In other words, watching the lesson and incorporating certain desirable aspects were mediated by a number of stages. Figure 1 schematically presents these stages:

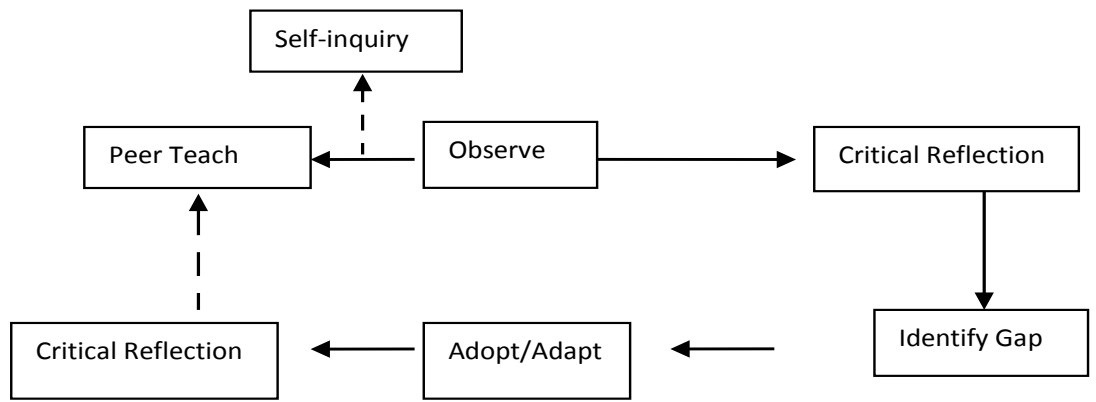

Figure 1. Observation Cycle for Self-enhancement 
The postulation of the stages presented in figure 1 is informed by the craft model and the reflective model (Wallace, 2010) of professional development of language teachers. Teaching as a craft postulates that it involves a set of skills that can be observed, imitated, transferred and can be perfected through continuous practice, whereas teaching as a reflective practice constantly involves self-inquiry, selfexploration and interaction with the self, apart from observing and interacting with other teachers. As demonstrated by Figure 1, the act of observing was preceded by self-inquiry about one's own teaching. Since self-inquiry instigates the whole process of observation and takes place within the potential observer, not noticeable for the outsider, it is kept before and above the actual observation and indicated by the dotted arrow. Inquiry about one's own teaching helped the observer identify his/her problem, gave him/her a purpose, rendering the observation more purposeful, focused and problem-oriented. Observation remains incomplete unless it is immediately followed by critical reflection. To put it another way, emulation of certain desirable practices is important, but not sufficient. Rather than attempting to emulate such practices, the observer is required to critically reflect on his/her own practices as well as the practices demonstrated by the peer. Critical reflection is instrumental in indentifying the gap in one's own teaching as well as the strengths of the peer's teaching. Conversely, it also helps the observer to identify his/her own strengths and the weaknesses in the lesson observed. In the former the observer fills the gap in his/her teaching with the strength(s) observed and learned from the peer's lesson, whereas in the latter the observer indentifies the peer's weakness(es) and identifies within himself/herself the better solution to address the problem. The observer adopts, or adopts and adapts, desirable practices indentified in the peer's teaching so as to enhance his own teaching. The observer-teacher tries out those practices perceived as desirable in his/her own teaching context. The teacher reflects on the effectiveness of such practices, which, if proved effective, are likely to be part of his/her own teaching.

The stages from observation of the peer's lesson to incorporation of the desirable practices into one's own teaching have been presented as though they are linear and sequential and occur separately. However, even those with little experience of teaching are aware of the fact that the journey from observation to teaching is cyclic, recursive and even messy. During the journey, the observer-teacher constantly swings back and forth between these stages.

\section{Conclusion and Implications}

Indentified as an integral part of teachers' professional development, peer observation, if carried out purposefully, critically and reflectively, equally benefits the observing teacher. Apart from the conventional practice of observing the lesson to provide the peer with constructive feedback, the role of peer observation for self-enhancement should be foregrounded in both pre-service and in-service teaching contexts, for as the responding teachers clearly recounted that they have employed peer observation as a transformatory tool, and observing their peers' teaching has proved a rewarding learning experience in one way or the other. This thread of conclusion also gets support from, among others, Peel (2005), Harmer (2007), Richards and Farrell (2010), and Richards and Lockhart (2010). Observing peers' teaching is likely to come to fruition only when observation is preceded by self-inquiry so that the observer realizes a certain gap in his/her own 
teaching and knows in advance what to observe or what to learn from the peer. The identification of the gap within oneself gives a clear purpose of observation, making it more focused. Learning by observing the peer's best practices, however, should not be mistaken for direct transfer of such practices to one's own teaching context. Rather, it requires the observing teacher to modify those practices to best fit his/her context. The critically aware observer journeys through different interrelated stages such as self-inquiry, observation and gap identification before trying out observed behaviors in his/her own teaching context. By implication, novice teachers in particular should be trained what to observe, how to observe and how to integrate what has been observed into his/her own teaching. They need to be oriented to, train in and supplied with the criteria for why, what and how aspects of observation so as to prevent them from passive or defocused observation.

\section{References}

Berg, B. L. (2007). Qualitative research methods for the social sciences. (6 $6^{\text {th }}$ ed.). Pearson and Allyn. Dean's Office (2018). Teaching practice (542). Kirtipur: Faculty of Education.

Harmer, J. (2007). The practice of English language teaching ( $4^{\text {th }}$ ed.). England: Pearson Longman. Head, K. \& Taylor, P. (1997). Readings in teacher development. Oxford: Heinemann ELT.

Hendry, G. D., \& Oliver, G. R. (2012). Seeing is believing: The benefits of peer observation. Journal of University Teaching \& Learning Practice, 9 (1), 7.

Krishnamurti, J. (1954). The observer is the observed. Ojai, California. $6^{\text {th }}$ Public Talk 1946.

Retrieved from http://jiddu-krishnamurti.net/en/1945-1948.

Peel, D. (2005). Peer observation as a transformatory tool? Teaching in Higher Education, 10(4), 489-504, DOI: 10.1080/13562510500239125.

Richards, J. \& Farrell, T. S. C. (2010). Professional development for language teachers: Strategies for teacher training ( $1^{\text {st }}$ South Asian ed.). Cambridge: Cambridge University Press.

Richards, J. \& Lockhart, C. (2010). Reflective teaching in second language classrooms( $1^{\text {st }}$ South Asian ed.). Cambridge: Cambridge University Press.

Victorian Department of Education and Training (2018). Peer observation, feedback and reflection: A practical guide for teachers. Melbourne: The Department of Education and Training.

Wallace, M. J. (2010). Training foreign language teachers: A reflective approach (1 ${ }^{\text {st }}$ South Asian ed.). Cambridge: Cambridge University Press.

Wragg, E.C. (2012). An introduction to classroom observation (Classic ed.). London \& New York: Routledge.

Bal Ram Adhikari is a lecturer in English Education at Mahendra Ratna Campus, Tahachal (TU). Mr. Adhikari has contributed to framing university courses, and designing and editing reading materials for universities in Nepal. 